\title{
Sequential thrombosis and bleeding in a woman with a prolonged activated partial thromboplastin time
}

\author{
Akpan Spencer ${ }^{1}$, Michael I Pearce ${ }^{1}$ and Paul RJ Ames ${ }^{2^{*}}$
}

\begin{abstract}
Simultaneous or sequential haemorrhage and thrombosis in the presence of a prolonged activated partial thromboplastin time (aPTT) is a rare occurrence: we describe the case a 37 year old lady who developed postdelivery deep vein thrombosis treated with low molecular heparin and warfarin followed a week later by extensive bruising over legs and forearms, a significant drop in haemoglobin and a very prolonged aPTT. Further tests revealed an acquired factor VIII inhibitor at 35 Bethesda Units. We discuss the clinical and laboratory implications and provide a literature review of simultaneous thrombophilia and haemophilia in the presence of a prolonged aPTT.
\end{abstract}

Keywords: thrombosis, acquired haemophilia, pregnancy, lupus anticoagulant

\section{Background}

The differential diagnosis of a prolonged aPTT (activated partial thromboplastin time) is manifold and necessitates an algorithm to indicate factor deficiencies or the presence of inhibitors that could be lupus like, heparin like or specific to a clotting factor [1]. A quick and correct laboratory diagnosis is of the utmost importance in the emergency setting when a clinician is faced with a critical haemorrhage in a previously healthy individual. We describe the sequential occurrence of thrombosis and haemorrhage developing over a nine day period in a young woman with a prolonged aPTT ratio.

\section{Case presentation Description}

A 37 year old woman presented to casualty for pain and swelling in the right calf; her Well's score was 5, Ddimer elevated at $422 \mathrm{ng} / \mathrm{ml}$ (cut-off limit $230 \mathrm{ng} / \mathrm{ml}$ ) and a Doppler ultrasound revealed a clot in the upper portion of the right femoral vein and in the deep veins of the right calf. With regards to thrombosis risk factors, she was 5 weeks post caesarean delivery, had been on

\footnotetext{
* Correspondence: paxmes@aol.com

2Department of Haematology, Airedale Foundation Trust, Steeton, BD20 6TD, UK

Full list of author information is available at the end of the article
}

oral contraception for the previous three weeks, had a body mass index of 24.5 (normal 18.5-24.9) had no varicose veins, and had not been on any long haul trips by either plane or car since delivery. Her personal history was uneventful, this being her first pregnancy during which she had no complications. There was no family history of thrombosis or recurrent miscarriages. Her aPTTr was 3.01 (normal range $0.88-1.16$ ) and prothrombin time ratio (PTr) was normal. Her Hb was 9.1 $\mathrm{g} / \mathrm{dl}$ with a slight microcytosis. Low molecular weight heparin (LMWH) at treatment dose was started embricated with warfarin then stopped after four days when her international normalised ratio (INR) was 2.3. A week later she re-attended casualty for spontaneous bruising on upper limbs and worsening of the pain and swelling in the right leg that was markedly ecchymotic. Blood tests on admission revealed $\mathrm{Hb} 8.1 \mathrm{~g} / \mathrm{dl}$, platelets $557 \times 10^{9} / \mathrm{L}$ and $\mathrm{C}$-reactive protein at $247 \mathrm{mg} / \mathrm{L}$ (normal $<5 \mathrm{mg} / \mathrm{L}$ ). Urine and blood cultures were negative. Since 1988 in Airedale the possibility of a bleeding disorder was tested by comparing the clotting times of two aPTT reagents, currently Synthesil (IL) as the reagent sensitive to factor inhibitors and deficiencies and Actin FS (Dade) as the reagent insensitive to factor inhibitors and deficiencies but sensitive to factor XII deficiency [2]. Unbeknown to the laboratory personnel the same
Ciomed Central

() 2011 Spencer et al; licensee BioMed Central Ltd. This is an Open Access article distributed under the terms of the Creative Commons Attribution License (http://creativecommons.org/licenses/by/2.0), which permits unrestricted use, distribution, and reproduction in any medium, provided the original work is properly cited. 
comparison can be used to detect a lupus anticoagulant [3]. Both assays are run on an automated coagulometer (TOP-CTS, Instrumentation Laboratories). The patient's INR was 2.3 (due to warfarin), the Synthesil aPTTr was disproportionately prolonged at 5.03 whereas the Actin FS aPTTr was 3.21 and a thrombin time was 12.8 " (normal 12-16.5") ruling out a possible residual effect of LMWH that had been stopped three days earlier. Given the prolongation of both aPTTs, the laboratory personnel informed the consultant haematologist of a possible factor inhibitor and pursued factor assays that revealed a factor VIII at $2 \mathrm{IU} / \mathrm{dl}$ (normal range 60-180 IU/dl), factor XII at $65 \mathrm{IU} / \mathrm{dl}$ (normal range 50-180 IU/dl), factor XI at $61 \mathrm{IU} / \mathrm{dl}$ (normal range 60-140 IU/dl) and factor IX at $46 \mathrm{IU} / \mathrm{dl}$ (normal range 50-150 IU/dl). A factor VIII inhibitor was detected at 35 Bethesda Units. A repeat Doppler US of the right lower limb did not show thrombus in the femoral vein but extensive haematoma in the calf obscuring the possibility of persistent thrombus. The following day her $\mathrm{Hb}$ had dropped to $6.9 \mathrm{~g} / \mathrm{dl}$ : warfarin was stopped and the patient was given a total dose of $8 \mathrm{mg}$ of recombinant VIIa intravenously, repeated two hourly 12 times after transfer to the Haemophilia Centre at Bradford Royal Infirmary. The patient was started on oral cyclophosphamide $100 \mathrm{mg}$ daily continued for six months and prednisolone $1 \mathrm{mg} /$ $\mathrm{kg}$ for 6 weeks, gradually tapered down over the ensuing five months: three weeks into immune suppression her factor VIII levels was $36 \mathrm{IU} / \mathrm{dl}$ and in June 2010 her factor VIII was $62 \mathrm{IU} / \mathrm{dl}$ with normal aPTTs. A thrombophilia screen done at the same time (plasma levels of protein $\mathrm{C}$, protein $\mathrm{S}$, antithrombin and gene testing for factor $\mathrm{V}$ Leiden and prothrombin mutation, anticardiolipin antibodies and lupus anticoagulant) was negative. At 16 months follow up she is inhibitor negative with normal plasma factor VIII level.

\section{Discussion}

Our patient shifted from deep vein thrombosis (DVT) to bleeding within the span of nine days: those involved in her care had not noticed that her aPTTr had been getting higher throughout her pregnancy (Table 1) and that it was markedly abnormal at her attendance for DVT. A factor VIII level at $2 \%$ and a factor VIII inhibitor at 35 Bethesda units were unequivocal with respect to pregnancy related acquired haemophilia: the latter is a lifethreatening antibody-mediated haemorrhagic disorder that occurs prevalently in people over 50 years of age presenting with bleeding and/or with a prolonged aPTT. The FVIII inhibitor may develop during and/or after pregnancy with a prevalence of $7 \%$ to $21 \%$ according to series. It appeared in the first pregnancy in $80 \%$ (16 of 20 ) of women and did not seem to recur with further pregnancies [4-10] though in one survey it recurred in the three women who had successive pregnancies [11]. In general the inhibitor is identified on occasions of overt bleeding: in one series $50 \%$ of bleeding occurred in the peri-partum period and in $50 \%$ within 30 days of delivery; in another series bleeding occurred pre-partum in two women, within three days of delivery in three and within 3-12 months in nine $[11,12]$. Another review showed that $3 \%$ of 27 women bled during pregnancy, $3 \%$ after an abortion, $15 \%$ immediately after delivery, $30 \%$ within 4 months and another $30 \%$ between 4 to 12 months of delivery; this review also shows that post-partum factor VIII inhibitor often disappears spontaneously [12].

However, prior to haemorrhage, our patient had suffered a DVT, quite a rare occurrence in the presence of a bleeding diathesis. In the absence of genetic or acquired thrombophilia, four haemophilia A patients developed spontaneous limb vein occlusions [13-16], one with a duplicated superficial femoral vein [16] whereas a haemophilia A youngster who was also factor $\mathrm{V}$ Leiden heterozygous suffered a spontaneous cerebral infarction [17].

Conversely two haemophilia A patients with inherited thombophilia developed a fatal pulmonary embolism and a DVT after a surgical challenge $[18,19]$ whereas a severe haemophilia A patient also factor V Leiden heterozygous suffered portal vein thrombosis after continuous infusion of F VIII [20]. DVT has been described also in a haemophilic A patient with factor VIII inhibitor 18 days after recombinant activated factor VII infusion [21].

Table 1 Evolution of coagulation tests since late pregnancy

\begin{tabular}{|c|c|c|c|c|c|c|c|}
\hline & \multicolumn{2}{|c|}{2009} & \multicolumn{4}{|c|}{2010} & \multirow[t]{2}{*}{ Range } \\
\hline & Sept 30 & Dec 31 & Jan 2 & Mar 3 & Mar 10 & Mar 12 & \\
\hline Gestational age (weeks) & 26 & 39 & 39 & & & & \\
\hline $\begin{array}{l}\text { Puerperium } \\
\text { (weeks) }\end{array}$ & & & & 5 & 6 & 6 & \\
\hline PTr & 1.00 & 0.90 & 1.03 & 1.26 & 2.05 & 2.32 & $0.9-1.12$ \\
\hline $\mathrm{aPTTr}$ & 1.01 & 1.23 & 1.32 & 3.01 & 9.31 & 5.03 & $0.88-1.16$ \\
\hline FNG (mg/dl) & 638 & $>700$ & 816 & 538 & 701 & 691 & $150-400$ \\
\hline
\end{tabular}

Prothrombin time ratio (PTr), activated partial thromboplastin time ratio (aPTTr) and fibrinogen (FNG) from the end of the second trimester of pregnancy (September 30) to end of puerperium (Mar 12) 
With regards to acquired haemophilia, a small series described a spontaneous DVT in a 60 year old woman and in an 80 year old man with splenic marginal zone lymphoma and a proximal leg vein occlusion after a femoral to popliteal by-pass in a 76 year old man [22]; pulmonary embolism developed in a 29 year old man who was on tranexamic acid to minimise bleeding episodes that were managed with recombinant factor VII when occurring acutely [23]: none of these patients had inherited or acquired thrombophilia.

Within the thrombosis setting a prolonged aPTTr may indicate the presence of a lupus anticoagulant (LA). In the flurry of the Friday afternoon when the acquired factor VIII inhibitor was detected, whilst the patient was administrated the first dose of recombinant factor VII and then transferred to Bradford Royal Infirmary, we overlooked that the Actin FS aPTTr was shorter than the Synthesil aPTTr (3.21 vs 5.03): a study comparing sensitive and insensitive reagents to the LA showed that the shortening of the aPTTr with Actin FS (the insensitive reagent) can be suggestive of LA even in patients on oral anticoagulants and/or with acquired haemophilia [3]. Hence we could not rule out that our patient also had a LA that was not detected on subsequent testing because of the immunosuppressive treatment she received. Of the four reported cases where acquired factor VIII inhibitor coexisted with LA the clinical phenotype was always bleeding [24-27]. With regards to haemophiliacs with anti-factor VIII inhibitors, one study showed a simultaneous LA detected by the dilute Russell viper venom time (DRVVT) (and Staclot LA) in 12 such patients [28] whereas a positive LA was more common in haemophiliacs with anti-factor VIIII inhibitors than in haemophiliacs without inhibitors either by DRVVT (IL-LAC screen and confirm) (22\% vs $10 \%)$ or by Staclot LA (Stago, France) (30\% vs 5\%).

\section{Conclusion}

Thrombosis and bleeding are the yin-yang of haemostasis and their simultaneous occurrence must alert us to the rarity and complexity of such occurrences and induce us to have a sharp insight in these cases: acquired haemophilia A developing post-partum is not uncommon, a vascular occlusion on the background of acquired haemophilia A followed by bleeding aggravated by warfarin is unusual indeed. Given the differences in the Synthesil and Actin FS aPTT ratios, we cannot rule out that DVT was also promoted by a LA that might have disappeared after immune suppressive treatment: strict adherence to existing guidelines for LA testing [29] should have lead us to perform also a DRVVT (screen and confirm) to shed further light on the thrombotic event.

\section{Consent}

The patient gave written informed consent for publication of this case report. A copy of the written consent is available for review by the Editor-in-Chief of this journal

\section{Author details}

${ }^{1}$ Department of Medicine, Airedale Foundation Trust, Steeton, BD20 6TD, UK. ${ }^{2}$ Department of Haematology, Airedale Foundation Trust, Steeton, BD20 6TD, UK.

\section{Authors' contributions}

PRJA conceived the report and coordinated the manuscript that was drafted by AS and completed by MIP. All authors read and approved the final manuscript.

\section{Competing interests}

The authors declare that they have no competing interests.

Received: 11 July 2011 Accepted: 27 October 2011

Published: 27 October 2011

\section{References}

1. Key N, Makris M, O'Shaughnessy D, Lilicrap D: Laboratory tests of hemostasis. Practical Hemostasis and Thrombosis. Chap 2 Wiley-Blackwell; 2009, 7-16.

2. Bowyer A, Smith J, Woolley AM, Kitchen S, Hampton KK, Maclean RM, et al: The investigation of a prolonged APTT with specific clotting factor assays is unnecessary if an APTT with Actin FS is normal. Int J Lab Hematol 2011, 33:212-218.

3. Brancaccio V, Ames PR, Glynn J, lannaccone L, Mackie IJ: A rapid screen for lupus anticoagulant with good discrimination from oral anticoagulants, congenital factor deficiency and heparin, is provided by comparing a sensitive and an insensitive APTT reagent. Blood Coagul Fibrinolysis 1997, 8:155-160.

4. Santoro C, Rago A, Biondo F, De Propris MS, De Vellis A, Guarini A, et al: Efficacy of rituximab treatment in postpartum acquired haemophilia A. Haemophilia 2008, 14:147-149.

5. Mytopher K, Dudebout J, Card R, Gilliland B: Acquired hemophilia A presenting post-partum. CMAJ 2007, 177:339-340.

6. Jost E, Kiefer P, Neulen J, Galm O, Osieka R: Post-partum acquired haemophilia after IVF without recurrence during a second pregnancy obtained by IVF. Hum Reprod 2007, 22:2348-2349.

7. Koeijers JJ, Vlasveld LT: A spontaneous haemarthrosis in a post-partal woman: a case of acquired haemophilia A. Ned Tijdschr Geneeskd 2005, 149:1164-1167.

8. Scully MF, Shublaq W, Oliver GD: Acquired hemophilia A presenting as a bleeding diathesis in a postpartum patient: diagnosis and management. J Obstet Gynaecol Can 2002, 24:430-432.

9. Santoro RC, Prejanò S: Postpartum-acquired haemophilia A: a description of three cases and literature review. Blood Coagul Fibrinolysis 2009, 20:461-465.

10. Baudo F, de Cataldo F: Italian Association of Haemophilia Centres (AICE): Register of acquired factor VIII inhibitors (RIIA). Acquired factor VIII inhibitors in pregnancy: data from the Italian Haemophilia Register relevant to clinical practice. BJOG 2003, 110:311-314.

11. Solymoss S: Postpartum acquired factor VIII inhibitors: results of a survey. Am J Hematol 1998, 59:1-4

12. Michiels JJ, Hamulyak K, Nieuwenhuis HK, Novakova I, van Vliet HH: Acquired haemophilia $\mathrm{A}$ in women postpartum: management of bleeding episodes and natural history of the factor VIII inhibitor. Eur J Haematol 1997, 59:105-109.

13. Bicer M, Yanar M, Tuydes O: Spontaneous deep vein thrombosis in hemophilia A: a case report. Cases J 2009, 2:6390.

14. Dargaud $Y$, Meunier S, Negrier C: Haemophilia and thrombophilia: an unexpected association! Haemophilia 2004, 10:319-326.

15. Kashyap R, Sharma Lm, Gupta S, Saxena R, Srivastava DN: Deep vein thrombosis in a patient with severe haemophilia A. Haemophilia 2006, 12:87-89. 
16. Stewart AJ, Manson LM, Dennis R, Allan PL, Ludlam CA: Thrombosis in a duplicated superficial femoral vein in a patient with haemophilia A. Haemophilia 2000, 6:47-49.

17. Oclay L, Gurgey A, Topaloglu H, Atay S, Parlak H, Firat M: Cerebral infarction associated with factor $V$ Leiden mutation in a boy with haemophilia A. Am J Hematol 1997, 58:189-190.

18. Butcher JH, Pasi KJ: Fatal postoperative pulmonary embolism in mild haemophilia. Haemophilia 2006, 12:179-182.

19. Pruthi RK, Heit JA, Green MM, Emiliusen LM, Nichols WL, Wilke JL, Gastineau DA: Venous thromboembolism after hip fracture surgery in a patient with haemophilia B and factor V Arg 506 Gln (factor V Leiden). Haemophilia 2006, 6:631-634.

20. Ettingshausen $C E$, Saguer IM, Kreuz W: Portal vein thrombosis in a patient with severe haemophilia A and F V G1691A mutation during continuous infusion of F VIII after intramural jejunal bleeding-successful thrombolysis under heparin therapy. Eur J Pediatr 1999, 158:180-182.

21. Van der Planken MG, Schrovens W, Vertessen F, Michiels JJ, Berneman ZN: Distal deep venous thrombosis in a haemophilia A patient with inhibitor and severe infectious disease, 18 days after recombinant activated factor VII transfusion. Blood Coagul Fibrinolysis 2002, 13:367-370.

22. Deitcher SR, Carman TL, Kottke-Marchant K: Simultaneous deep venous thrombosis and acquired factor VIII inhibitor. Clin Appl Thromb Hemost 2002, 8:375-379.

23. Taparia M, Cordingley FT, Leahy MF: Pulmonary embolism associated with tranexamic acid in severe acquired haemophilia. Eur J Haematol 2002, 68:307-309.

24. Ballard HS, Nyamuswa G: Life-threatening haemorrhage in a patient with rheumatoid arthritis and a lupus anticoagulant coexisting with acquired autoantibodies against factor VIII. Br J Rheumatol 1993, 32:515-517.

25. Grossmann R, Wankmüller H, Schwender S, Kirschner J, MansouriTaleghani B, Keller $\mathrm{P}$, et al: The diagnosis and therapy of acquired factorVIII inhibitors in combination with lupus anticoagulants. Dtsch Med Wochenschr 1996, 121:906-910.

26. Biron C, Durand L, Lemkecher T, Dauverchain J, Meunier L, Meynadier J, et al: Simultaneous occurrence of lupus anticoagulant, factor VIII inhibitor and localized pemphigoid. Am J Hematol 1996, 51:250-251.

27. Taher A, Abiad R, Uthman I: Coexistence of lupus anticoagulant and acquired haemophilia in a patient with monoclonal gammopathy of unknown significance. Lupus 2003, 12:854-856.

28. Blanco AN, Cardozo MA, Candela M, Santarelli MT, Pérez Bianco R, Lazzari MA: Anti-factor VIII inhibitors and lupus anticoagulants in haemophilia A patients. Thromb Haemost 1997, 77:656-659.

29. Pengo V, Tripodi A, Reber G, Rand JH, Ortel TL, Galli M, et al: Update of the guidelines for lupus anticoagulant detection. Subcommittee on Lupus Anticoagulant/Antiphospholipid Antibody of the Scientific and Standardisation Committee of the International Society on Thrombosis and Haemostasis. J Thromb Haemost 2009, 7:1737-1740.

doi:10.1186/1477-9560-9-16

Cite this article as: Spencer et al: Sequential thrombosis and bleeding in a woman with a prolonged activated partial thromboplastin time. Thrombosis Journal 2011 9:16.

\section{Submit your next manuscript to BioMed Central and take full advantage of:}

- Convenient online submission

- Thorough peer review

- No space constraints or color figure charges

- Immediate publication on acceptance

- Inclusion in PubMed, CAS, Scopus and Google Scholar

- Research which is freely available for redistribution

Submit your manuscript at www.biomedcentral.com/submit
Biomed Central 